OPEN ACCESS

Edited by:

Nuno Sousa,

Instituto de Pesquisa em Ciências da Vida e da Saúde (ICVS), Portugal

Reviewed by: Antonia Manduca, Aix-Marseille Université, France Senthilkumar S. Karuppagounder, Johns Hopkins University, United States

*Correspondence: Francisca Pérez-Severiano fperez@innn.edu.mx

Received: 16 February 2018

Accepted: 16 August 2018 Published: 03 September 2018

Citation:

Martínez-Lazcano JC López-Quiroz A, Alcantar-Almaraz R, Montes S, Sánchez-Mendoza A Alcaraz-Zubeldia $M$, Tristán-López LA Sánchez-Hernández BE, Morales-Martínez A, Ríos $C$ and Pérez-Severiano F (2018) A Hypothesis of the Interaction of the Nitrergic and Serotonergic Systems in Aggressive Behavior Induced by Exposure to Lead Front. Behav. Neurosci. 12:202 doi: 10.3389/fnbeh.2018.00202

\section{A Hypothesis of the Interaction of the Nitrergic and Serotonergic Systems in Aggressive Behavior Induced by Exposure to Lead}

\author{
Juan Carlos Martínez-Lazcano ${ }^{1,2}$, Alfredo López-Quiroz ${ }^{1}$, Rocío Alcantar-Almaraz ${ }^{1}$, \\ Sergio Montes ${ }^{1}$, Alicia Sánchez-Mendoza ${ }^{3}$, Mireya Alcaraz-Zubeldia ${ }^{1}$, Luis Antonio \\ Tristán-López ${ }^{1}$, Beatriz Eugenia Sánchez-Hernández ${ }^{4}$, Adriana Morales-Martínez ${ }^{1}$, \\ Camilo Ríos ${ }^{1}$ and Francisca Pérez-Severiano ${ }^{1 *}$ \\ 'Departamento de Neuroquímica, Instituto Nacional de Neurología y Neurocirugía (INNN), Mexico City, Mexico, \\ ${ }^{2}$ Departamento de Neurofisiología, Instituto Nacional de Neurología y Neurocirugía (INNN), Mexico City, Mexico, \\ ${ }^{3}$ Departamento de Farmacología, Instituto Nacional de Cardiología Ignacio Chávez, Mexico City, Mexico, ${ }^{4}$ Departamento de \\ Genética, Instituto Nacional de Ciencias Médicas y Nutrición Salvador Zubirán, Mexico City, Mexico
}

The effects caused by exposure to lead $(\mathrm{Pb})$ are still considered as a relevant health risk despite public policies aimed to restricting the use of this element. The toxicity limit in the blood (10 $\mu \mathrm{g} / \mathrm{dL}$, established by the Center for Disease Control and Prevention) has been insufficient to prevent adverse effects and even lower values have been related to neurobehavioral dysfunctions in children. Currently, there is not a safe limit of exposure to $\mathrm{Pb}$. A large body of evidence points to environmental pollutant exposure as the cause of predisposition to violent behavior, among others. Considering the evidence by our group and others, we propose that $\mathrm{Pb}$ exposure induces alterations in the brain vasculature, specifically in nitric oxide synthases (NOS), affecting in turn the serotonergic system and leading to heightened aggressive behavior in the exposed individuals. This review article describes the consequences of $\mathrm{Pb}$ exposure on the nitrergic and serotonergic systems as well as its relationship with aggressive behavior. In addition, it summarizes the available therapy to prevent damage in gestation and among infants.

Keywords: lead exposure, central nervous system, epigenetic, nitrergic and serotonergic systems, aggressive behavior

\section{INTRODUCTION}

\section{Lead and Its Effects as Public Health Matter}

Lead $(\mathrm{Pb})$ is a non-essential element for humans. It is considered one of the most common toxic metals in the environment and is frequently used in a variety of products, primarily in lead car batteries. Other uses of lead include leaded gasoline, paints, ceramics, ammunition, water pipes, solders, cosmetics, hair dye, farm equipment, airplanes, shielding for $\mathrm{x}$-ray machines and in the manufacture of corrosion and acid resistant materials used in the building industry (Sanders et al., 2009). The chronic exposure to this pollutant remains a public health problem that affects several human body systems including nervous, reproductive, and circulatory. In bones, nails and teeth, $\mathrm{Pb}$ is deposited and may remain accumulated throughout life. In pregnant women, it has been reported 
that $\mathrm{Pb}$ can cross the placental barrier and is equally distributed in the mother and fetus (Fontana et al., 2013). Children are the most susceptible population to $\mathrm{Pb}$ exposure: they have been reported to show alterations in cardiac function, encephalopathy, genotoxicity, cognitive deficits, language alterations, antisocial behavior and juvenile delinquency after exposure to the metal (Amos-Kroohs et al., 2016; Sampson and Winter, 2018). Evidence suggests that the rate of violent crimes in several countries is related to the levels of $\mathrm{Pb}$ in blood among the population, even in individuals at school age. The harmful effects of $\mathrm{Pb}$ have been described to be present up to 20 years after the initial exposure, evidencing that the metal causes short- and long-term effects (Carpenter and Nevin, 2010). Lead enters the human body when we consume contaminated water, breathe a polluted environment and use contaminated pottery still releasing $\mathrm{Pb}$ in the kitchen or when storing water, for example. Recent cases as the water poisoning in Flint, Michigan in 2015 and the evacuation of an entire neighborhood contaminated by a smelting plant in East Chicago, Indiana in 2016 have shed light on the contemporary perils of lead contamination (Goodnough, 2016a,b). Although environmental reforms such as the bans on $\mathrm{Pb}$ in gasoline and paint in the 1970's were deemed victories for public health (Needleman, 2004; Markowitz and Rosner, 2013), Pb toxicity is far from being a hazard of the past. High levels of the metal have recently been found in several cities in the United States (Pell and Schneyer, 2016) and in both developed and developing countries around the world (Tong et al., 2000). The situation is especially important to Mexico because of the prevailing high environmental pollution and exposure to $\mathrm{Pb}$ in lead-glazed pottery that does not comply with the official standards. The Mexican government has passed bills related to the production and evaluation of ceramic (Norma Oficial Mexicana, 2007) as well as a program encouraging ceramic producers to use alternative unleaded glaze in pottery (National Program to Adopt Lead-Free Glazed Pottery, FONART, Mexico). Despite these actions, the levels of $\mathrm{Pb}$ in blood among the population are a concern mainly because of the levels of $\mathrm{Pb}$ in the environment, (Fontana et al., 2013; Amos-Kroohs et al., 2016), the easy access of the metal to the body and the manufacturers' non-compliance with official standards (Norma Oficial Mexicana, 2007; DiazRuiz et al., 2017). Therefore, $\mathrm{Pb}$ remains an environmental risk in countries like Mexico regardless of the restrictions in its use.

\section{How to Address the Problem of Neurological Alterations Due to $\mathrm{Pb}$ Exposure and Their Relationship With Behavioral Changes?}

It is widely recognized that $\mathrm{Pb}$ exposure exerts toxic effects in every organ system, especially the central nervous system (CNS). Brain damage induced by $\mathrm{Pb}$ may result in a variety of neurological disorders, including mental retardation (Sanders et al., 2009) Alzheimer's disease, Parkinson's disease (MonnetTschudi et al., 2006) and schizophrenia (Opler et al., 2008). In addition, the neurotoxic effects of lead exposure may cause behavioral problems such as attention deficit hyperactivity disorder, juvenile delinquency, and criminality (Pihl and Ervin, 1990; Wright et al., 2008). In addition, lead can adversely affect general intellectual functioning (Sanders et al., 2009), visuospatial function (Weisskopf et al., 2007), and verbal learning and memory (Bleecker et al., 2005). Furthermore, recent studies have demonstrated that executive function may be at risk in Pb-induced neurotoxicity (Trope et al., 2001; Canfield et al., 2004). Most works on executive dysfunction focus on children and only a few aim to analyze adult workers exposed to $\mathrm{Pb}$ (Trope et al., 2001; Canfield et al., 2004; Sanders et al., 2009). Since adult occupational exposure and childhood developmental exposure to $\mathrm{Pb}$ cause cognitive and behavioral alterations (Sanders et al., 2009; National Toxicology Program, 2012), studies on workers exposed to the pollutant is needed to clarify $\mathrm{Pb}$ neurotoxicity related to executive functions.

The legacy of $\mathrm{Pb}$, both historical and contemporary, carries important theoretical implications for the study of crime. An association between lead exposure and cognitive impairment has been documented in medical research (Lanphear et al., 2000; Canfield et al., 2003; Reuben et al., 2017), and several criminologists have long argued that there is a connection between cognitive ability and delinquency (Farrington, 1998). Similarly, there is evidence that $\mathrm{Pb}$ aggravates hyperactivity, impulsive behavior, and mental health problems (Braun et al., 2006; Winter and Sampson, 2017), which have been shown to predict delinquency (Elliott et al., 1989; Moffitt, 1990; Wright et al., 2008). Reyes (2015) reported an association between $\mathrm{Pb}$ exposure and subsequent delinquency and crime activities.

Animal models must be used to evaluate the molecularbiological processes related to exposure to pollutants. Particularly, $\mathrm{Pb}$ is orally administered to the pregnant and/or lactating female to evaluate the resulting consequences of chronic exposure to low levels of $\mathrm{Pb}$ in young animals during gestation and development. The experimental models that start with exposure during gestation and conclude at weaning cover most of the neurogenesis and neuronal development (Virgolini and Cancela, 2014). In spite of its limitations, the oral administration of $\mathrm{Pb}$ to the pregnant mother and/or infant is the animal model most frequently used to evaluate the consequences of chronic exposure to low levels of $\mathrm{Pb}$ during development. The model allows for behavioral evaluation of the subjects after 70-90 days of exposure and age (de Souza Lisboa et al., 2005; Weston et al., 2014). Additionally, this scheme of exposure enables the evaluation of epigenetic effects (DNA methylation, histone modifications, and ncRNAs regulation) induced by exposure to $\mathrm{Pb}$. This administration scheme has allowed researchers to evaluate the effect of prenatal exposure to lead and the predisposition to aggressive behavior as well as the correlation between these events and the regulation of the nitrergic and serotonergic systems in the brain. The notions of a relationship between serotonergic and nitrergic systems and between these systems and aggressiveness have been recently explored by studies that evaluated the effect of the inhibition of neuronal nitric oxide synthases (nNOS) 
activity on the serotonergic system and its relationship with aggressive behavior (Carreño-Gutiérrez et al., 2017). This type of studies helps to identify the molecular targets of the damage produced by exposure to $\mathrm{Pb}$, the degree of damage in brain development and the behavioral alterations caused.

\section{Lead as a Possible Cause of Aggressive Behavior}

The exposure to environmental pollutants as a predisposition factor of violent behavior has received little attention since violent and antisocial behaviors are usually attributed to socioeconomic factors, including poverty, deficient education and family instability. There is evidence that violent behavior is more frequent among individuals with low intellectual quotient (Amos-Kroohs et al., 2016), a neurobehavioral pattern that has been described in children exposed to $\mathrm{Pb}$ at an early stage. Recently, Sampson and Winter (2018) published an article about the social consequences of exposure to lead, highlighting criminal behavior in young people exposed to lead, and suggesting that some factors can be explained through the hypothesis of displacement of $\mathrm{Ca}^{++}$by $\mathrm{Pb}^{++}$(Sampson and Winter, 2018). The toxicity mechanisms through which $\mathrm{Pb}$ promotes neurological alterations, in particular aggressiveness, in the CNS have not been fully described in humans or experimental models. In this review article, we propose a molecular hypothesis that involves modifications in the activity and expression of nNOS, and a consequent modification in serotonin 5-hydroxytryptamine (5-HT) and its 5-HT1B receptor levels in animals that present an increase in aggressive behavior after lead exposure. It is important to note that there are other neurotransmitters and hormonal systems involved in aggressive behavior, such as dopamine and testosterone. Additionally, there is evidence indicating that NOS are $\mathrm{Pb}$ targets in the brain vasculature (García et al., 1999). Moreover, some reports indicate that the decrease in nitric oxide (NO) has an effect upon the serotonergic pathway and aggressive behavior (Chiavegatto and Nelson, 2003; Martínez-Lazcano et al., 2007; Sansar et al., 2012). In Soria et al. (2008) collected and integrated available information on the participation of 5-HT in the modulation of aggressive behavior in several animal species, including humans.

Considered an inhibitor of aggressiveness, 5-HT reduces impulsivity at high concentrations while its reduction leads to increased intensity and frequency of aggressive and antisocial reactions that are more impulsive than premeditated. The exact mechanisms of $\mathrm{Pb}$ neurotoxicity and its effects on the aminergic system in rat brain remain unclear, but they might exist at different levels, altering the concentration of 5-HT and its metabolite, 5-hydroxyindoleacetic acid (5-HIAA), suggesting an effect of $\mathrm{Pb}$ on L-Monoamine oxidases (MAO), a family of enzymes that catalyze monoamine oxidation (Basha et al., 2012). There are reports on dissociation from synthesis, storage, and release of 5-HT with effects on the formation of 5-HIAA (Lasley et al., 1984) and alterations in both the synthesis and metabolism of serotonin receptors
(Leret et al., 2002; Sansar et al., 2012). In consequence, $\mathrm{Pb}$ produces an alteration in brain functions, which could be attributed to an imbalance in endogenous neurotransmitters, like dopamine and 5-HT. Because of this, human and animal exposure to $\mathrm{Pb}$ during early development might alter the normal levels of 5-HT, metabolite 5-HIAA and the serotonin transporter (5HTT; Hou et al., 2012), producing significant changes in 5-HT replacement and, in consequence, aggressive behavior (Wang et al., 2012).

\section{Evidence of the Relation Between NOS, 5-HT and Aggressiveness}

In mice and rats, male aggression is a resource to exclude other males from a breeding unit or maintain dominance within a more complex social structure. From an evolutive perspective, aggressive behavior displayed by the dominant male is highly adaptive since territorial males have access to breeding; therefore, they have greater reproductive success than subordinates and non-territorial males. In this case, there is a close relationship between the ability to fight, rank, and perform breeding events (Ferrari et al., 2006). In unstable rodent social groups, recurring conflicts compromise the immune system, divert energy and time of breeding and foraging, increase the risk of injury, interrupt circadian rhythms of endocrine and cardiovascular functions, and shorten lifespan (Fleshner et al., 1989; Stefanski, 2001). Studies carried out by Carreño-Gutiérrez et al. (2017) demonstrated the relationship between the nitrergic and serotonergic systems. Using zebra fish and knockout mice (-/-), they showed a decrease in the production of $\mathrm{NO}$ and described a reduction of 5-HT in MAO activity and dopamine levels. Also, the treatment of rats with NO donor molsidomine increased 5-HT metabolism (LorencKoci et al., 2013) whereas nNOS inhibition with $\mathrm{N} \omega$-nitroL-arginine (L-NAME) decreases neurotransmitter turnover in mice (Karolewicz et al., 2001), further linking NO to MAO. In 1999, our team showed that mice exposed to doses of lead acetate $(250,500$ and $1,000 \mathrm{ppm})$ in drinking water showed dose-dependent increasing concentrations of $\mathrm{Pb}$ in brain tissue. These results correlated with the activity of calcium-dependent NOS (cNOS; García et al., 1999) and learning and memory (García et al., 2004). Endothelial NOS (eNOS) and nNOS, both calcium-dependent, participate in the control of vascular activity in the CNS. Then, the alterations found in cNOS activity might also affect vascular functions in the CNS. In some cases, aggressive behavior is attributed to cognitive deficits, speech alterations and low intellectual quotient. Several studies have demonstrated that NOS is involved in plasticity brain changes underlying long term potentiation (LTP) in the hippocampus (Hawkins et al., 1998; Ko and Kelly, 1999; Schuman and Madison, 1991) and formation of memory in several tasks (Böhme et al., 1993; Zhang et al., 1998; Zou et al., 1998). García et al. (2004) proved that the exposure to $\mathrm{Pb}$ blocks LTP induction in the hippocampus, which is associated to a decrease in the number of tasks involving learning and memory. Knock-out 


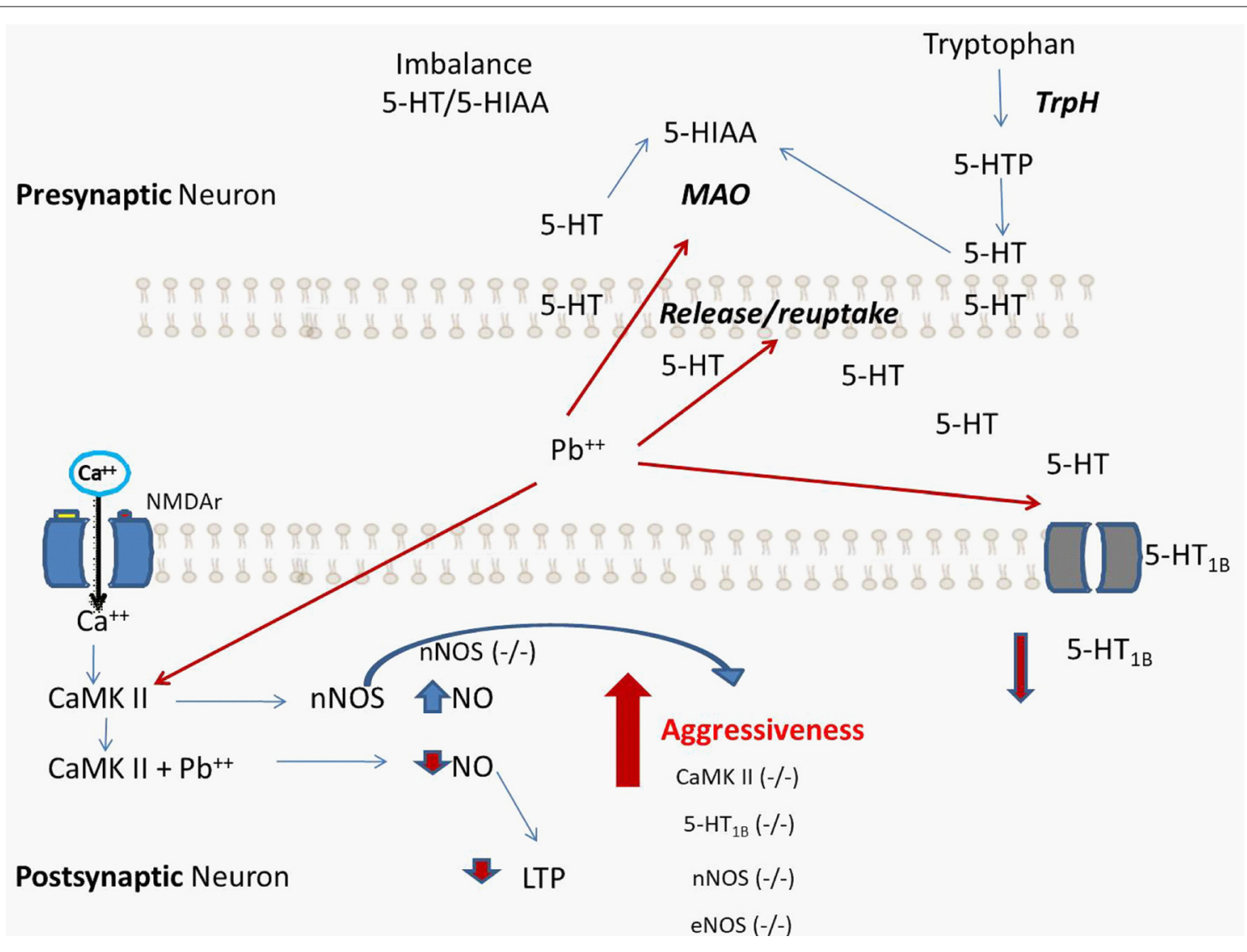

FIGURE 1 | Proposed hypothetical scheme that summarizes the processes caused by lead (Pb) exposure. The increase in aggressive behavior is a direct consequence of alterations in the vascular-nitrergic-serotonergic system by interaction with $\mathrm{Pb}$. The processes that lead to neurochemical alterations caused by Pb coincide with the behavioral alterations found in genetically modified experimental models, such as knock-out mouse for 5-HT $1 \mathrm{~B}$ (-/-), endothelial NOS (eNOS; -/-), and neuronal nitric oxide synthases (nNOS; -/-). 5-HT: serotonin, 5-HIAA: 5-hydroxyindoleacetic acid, MAO: monoamino oxidase, TrpH: tryptophan Hydroxylase.

mice for eNOS and nNOS show reduction and loss of LTP (Hopper and Garthwaite, 2006) as well as increased aggressive behavior (Huang et al., 1993, 1995). Furthermore, eNOS knock-out mice show severe alterations in angiogenesis, leading to vascular problems.

A significant portion of individual differences in aggressive behavior have been attributed to genetic factors. For this reason, many studies have conducted research on aggressive behaviors, in endogamic and exogamic mouse strains and recombinant or selected lines, to map or identify genes of aggressive behavior and determine the mechanisms through which genes influence aggression. These classic genetic studies have selected animals with different levels of aggressive behavior, suggesting that the tendency of getting involved in an intra-specific attack is a hereditary characteristic (Ferrari et al., 2006). In addition to these studies, the knock-out mouse generation produced strains that developed increased aggressive behavior, such as 5 -HT1B $(-/-)$, eNOS $(-/-)$, and nNOS $(-/-)$, among others. Furthermore, nNOS (-/-) mice show alterations in 5-HT metabolism (Chiavegatto and Nelson, 2003) while eNOS (-/-) animals display vascular alterations. Based on this information, increased aggressive behavior by $\mathrm{Pb}$ exposure is likely a direct consequence of alterations in the vascular-nitrergic-serotonergic systems (Figure 1). Additionally, NO has already been shown to modulate monoamine reuptake by indirect phosphorylation or direct S-nitrosylation of SERT, NET and DAT (Miller and Hoffman, 1994; Chanrion et al., 2007). Similarly, MAO activity is reduced by phosphorylation or S-nitrosylation. A negative feedback loop acting at gene transcription level could then lead to heightened levels of MAO expression in compensation for the reduced enzyme activity. Also, NO can alter neurotransmitter release via phosphorylation of synaptosomal proteins (Hirsch et al., 1993), thereby altering the amount of time in which neurotransmitters interact with their receptors.

\section{Preventive and Therapeutic Treatment Schemes to Prevent the Entry of $\mathrm{Pb}$ to the Organism}

Maternal $\mathrm{Pb}$ exposure significantly influences embryonic and fetal development and is directly related to pregnancy impairment outcomes, including low birth weight, intellectual and learning disabilities and abnormal behavior (Sanders et al., 2009). Therefore, the design of studies on exposure to $\mathrm{Pb}$ during 
the embryonic stage aimed to create schemes or therapeutic treatments for preventing exposure to $\mathrm{Pb}$ and/or stopping any mechanism of damage related to this metal. For these reason, actions for detoxification and therapeutic chelation strategies are necessary. Some of the current therapeutic proposals are explained below.

\section{Ascorbic Acid}

In a study by Chang et al. (2012), pregnant Sprague-Dawley rats exposed to $0.2 \% \mathrm{~Pb}$ were treated with ascorbic acid (100 mg/kg/day) during pregnancy and lactation. The study proved that the treatment could ameliorate $\mathrm{Pb}$-induced oxidative damage in the developing hippocampus and recover protein levels of $\mathrm{Cu} / \mathrm{ZnSOD}, \mathrm{MnSOD}$ and catalase (CAT). Ascorbic acid also reduced the number of damaged cells in cornu ammonis 1 and 2 and dentate gyrus of hippocampus. Similarly, MassóGonzález and Antonio-García (2009) showed that ascorbic acid attenuates $\mathrm{Pb}$-induced oxidative stress in liver and kidney using in vitro and in vivo models. However, the precise mechanism by which ascorbic acid is responsible for the beneficial effects on antioxidant systems in the developing rat brain remains unclear. These results might help to find protection strategies to prevent developmental deficits and cognitive dysfunctions observed in childhood after in utero low-level $\mathrm{Pb}$ exposure (Chang et al., 2012).

\section{Antioxidant MitoQ}

MitoQ is a known mitochondrial-specific antioxidant with ONOO-scavenging activity that accumulates 500-fold in the mitochondrial matrix by the use of the mitochondrial membrane potential. This antioxidant efficiently mitigated mitochondrial complexes II, III and IV inhibition, ONOO-mediated inhibition, increased mitochondrial ATP production, restored mitochondrial membrane potential, and decreased caspases 3 and 9 activity upon $\mathrm{Pb}$ exposure. MitoQ also suppressed synaptosomal lipid peroxidation and protein oxidation, showing diminished nitrite production 3-nitrotyrosine protein binding. A treatment based on $500 \mu \mathrm{g}$ MitoQ administered orally to rats for 15 days after exposure to $100-400$ ppm lead acetate in drinking water protected against damage induced by the metal. Also, SHSY5Y cells exposed to increasing concentrations of $\mathrm{Pb}(5,15$ and $15 \mu \mathrm{M})$ showed a dose-dependent loss of cell viability, which was reverted by concomitant presence of MitoQ (50 nM). MitoQ has been also proved to reduce alterations by mitochondrial dysfunction in both in vivo and in vitro models of $\mathrm{Pb}$ exposure and ameliorate oxidative and nitrosative parameters, demonstrating to be an effective neuroprotective agent against $\mathrm{Pb}$ neurotoxicity (Maiti et al., 2017).

\section{Zinc Diet}

Recently, Kumar et al. (2017) reported that zinc administered as a dietary supplement (10 and $20 \mathrm{mg} / \mathrm{kg}$ ) promoted immunebiochemical plasticity and protected against multiple stresses in $\mathrm{Pb}$ exposure damage in fish (Pangasius hypophthalmus). Zinc is a key essential element that acts as a growth promoter and plays a significant part in several other cellular functions including cell proliferation, cofactor reproduction, immune function and defense against free radicals. It's considered a vital intracellular trace element for genetic stability and function. Zinc acts as cofactor for several metabolic pathways in many enzymatic systems and is also a major component of a number of metalloenzymes, such as carbonic anhydrase, carboxypeptidase, alcohol dehydrogenase, glutamic dehydrogenase and superoxide dismutase (Kumar et al., 2017).

\section{$\beta$-Asarone (cis-2.4,5-trimethoxy-1-allyl phenyl)}

$\beta$-asarone is an active oriental herb component which reverts damage inflicted by $\mathrm{Pb}$ over spatial memory, possibly through synaptogenesis (Yang et al., 2016). Developmental rat pups were exposed to $\mathrm{Pb}$ throughout lactation period and $\beta$-asarone $(10,40 \mathrm{mg} / \mathrm{kg}$, respectively) was administered intraperitoneally from postnatal day 14-21. Also, adult rats were exposed to $\mathrm{Pb}$ from embryo stages to 11 weeks of age and $\beta$-asarone $(2.5,10,40 \mathrm{mg} / \mathrm{kg}$, respectively) was given rats aged 9-11 weeks. $\beta$-asarone crossed the blood brain barrier and attenuated $\mathrm{Pb}$-induced spine density reduction in hippocampal CA1 and dentate gyrus areas in a dose-dependent manner both in developmental and adult rats. Additionally, it has been proved that $\mathrm{Pb}$-induced impairments of learning and memory are partially reverted after treatment with this molecule. Also, $\beta$-asarone effectively up-regulates the protein expression of NR2B, Arc and Wnt7a, which have been suppressed by $\mathrm{Pb}$ exposure. The above mentioned results suggest neuroprotective properties of $\beta$-asarone against $\mathrm{Pb}$-induced memory impairments and an effect possibly related to the regulation of synaptogenesis, mediated via Arc/Arg3.1 and Wnt pathway. Traditional use and clinical reports showed that $\beta$-asarone is effective for the treatment of learning and memory deficits; therefore, it is likely to manage memory impairment following chronic $\mathrm{Pb}$ exposure (Yang et al., 2016).

\section{PERSPECTIVES AND CONCLUSIONS}

The signs and symptoms induced by the $\mathrm{Pb}$ exposition can appear immediately after exposure or may be delayed and include loss of memory, vision, cognitive and behavioral problems, and brain damage/mental retardation. Most early studies concentrated on the neurocognitive effects of lead, but recently higher exposures have been associated with such morbidities as antisocial behavior, delinquency, and violence (Hwang, 2007). Several hypotheses have been proposed to explain the mechanism of lead toxicity on the CNS, including the participation of the nitrergic and serotonergic systems. After considering the information available, we propose that the increase of aggressive behavior is a consequence of alterations in the vascular-nitrergic-serotonergic system by interaction with $\mathrm{Pb}$, without forgetting the influence that other molecules such as dopamine and testosterone could have on aggressive behavior. However, several experimental studies are still needed to fully reaffirm this hypothesis, so that a pharmacological strategy can be proposed as a therapeutic target and applied from the embryonic stage to restore the neurological damage 
caused by lead in the CNS. Studies will have to obtain the scientific proof to demonstrate that the exposure to $\mathrm{Pb}$ promotes violent behaviors among the subjects exposed to the metal. This behavioral alteration currently represents a serious matter of public health and carries an elevated social cost.

Additionally, we seek to prevent and/or reduce environmental pollution by $\mathrm{Pb}$ and other toxic particles to prevent irreversible brain damage in adolescence and development of CNS from gestation stages. This panorama demonstrates the lack of knowledge regarding the mechanism of neuronal damage caused by the exposure to a pollutant and, at the same time, the need to recreate human environmental exposure at experimental level to obtain further understanding of the damage mechanisms in brain development and altered behavior.

\section{REFERENCES}

Amos-Kroohs, R. M., Graham, D. L., Grace, C. E., Braun, A. A., Schaefer, T. L., Skelton, M. R., et al. (2016). Developmental stress and lead (Pb): effects of maternal separation and/or $\mathrm{Pb}$ on corticosterone, monoamines and blood $\mathrm{Pb}$ in rats. Neurotoxicology 54, 22-33. doi: 10.1016/j.neuro.2016.02.011

Basha, D. C., Rani, M. U., Devi, C. B., Kumar, M. R., and Reddy, G. R. (2012). Perinatal lead exposure alters postnatal cholinergic and aminergic system in rat brain: reversal effect of calcium co-administration. Int. J. Dev. Neurosci. 30, 343-350. doi: 10.1016/j.ijdevneu.2012.01.004

Bleecker, M. L., Ford, D. P., Lindgren, K. N., Hoese, V. M., Walsh, K. S., and Vaughan, C. G. (2005). Differential effects of lead exposure on components of verbal memory. Occup. Environ. Med. 62, 181-187. doi: 10.1136/oem.2003. 011346

Böhme, G. A., Bon, C., Lemaire, M., Reibaud, M., Piot, O., Stutzmann, J. M., et al. (1993). Altered synaptic plasticity and memory formation in nitric oxide synthase inhibitor-treated rats. Proc. Natl. Acad. Sci. U S A 90, 9191-9194. doi: 10.1073/pnas.90.19.9191

Braun, J. M., Kahn, R. S., Froehlich, T., Auinger, P., and Lanphear, B. P. (2006). Exposures to environmental toxicants and attention deficit hyperactivity disorder in U.S. children. Environ. Health Perspect. 114, 1904-1909. doi: 10.1289/ehp.9478

Canfield, R. L., Gendle, M. H., and Cory-Slechta, D. A. (2004). Impaired neuropsychological functioning in lead-exposed children. Dev. Neuropsychol. 26, 513-540. doi: 10.1207/s15326942dn2601_8

Canfield, R. L., Henderson, C. R. Jr., Cory-Slechta, D. A., Cox, C., Jusko, T. A., and Lanphear, B. P. (2003). Intellectual impairment in children with blood lead concentrations below $10 \mu \mathrm{g}$ per deciliter. N. Engl. J. Med. 348, 1517-1526. doi: $10.1056 /$ nejmoa022848

Carpenter, D. O., and Nevin, R. (2010). Environmental causes of violence. Physiol. Behav. 99, 260-268. doi: 10.1016/j.physbeh.2009.09.001

Carreño-Gutiérrez, H., O’Leary, A., Freudenberg, F., Fedele, G., Wilkinson, R., Markham, E., et al. (2017). Nitric oxide interacts with monoamine oxidase to modulate aggression and anxiety-like behaviour. Eur. Neuropsychopharmacol. doi: 10.1016/j.euroneuro.2017.09.004 [Epub ahead of print].

Chang, B. J., Jang, B. J., Son, T. G., Cho, I. H., Quan, F. S., Choe, N. H., et al. (2012). Ascorbic acid ameliorates oxidative damage induced by maternal low-level lead exposure in the hippocampus of rat pups during gestation and lactation. Food Chem. Toxicol. 50, 104-108. doi: 10.1016/j.fct.2011.09.043

Chanrion, B., Mannoury la Cour, C., Bertaso, F., Lerner-Natoli, M., Freissmuth, M., Millan, M. J., et al. (2007). Physical interaction between the serotonin transporter and neuronal nitric oxide synthase underlies reciprocal modulation of their activity. Proc. Natl. Acad. Sci. U S A 104, 8119-8124. doi: 10.1073/pnas.0610964104

Chiavegatto, S., and Nelson, R. J. (2003). Interaction of nitric oxide and serotonin in aggressive behavior. Horm. Behav. 44, 233-241. doi: 10.1016/j.yhbeh.2003. 02.002

\section{AUTHOR CONTRIBUTIONS}

All authors had full access to all the information in this review article and take responsibility for the integrity. JM-L, FP-S, AL-Q and RA-A designed the review. SM, MA-Z, CR, BS-H and LT-L contributed to order the bibliographic work of lead exposition and epigenetic consequences. AS-M and JM-L designed the hypothetic scheme. FP-S, AM-M and JM-L wrote the manuscript and had primary responsibility for the final content.

\section{FUNDING}

This work was supported by Conacyt Research grant \#241911 (Consejo Nacional de Ciencia y Tecnología).

de Souza Lisboa, S. F., Gonçalves, G., Komatsu, F., Queiroz, C. A., Almeida, A. A., and Moreira, E. G. (2005). Developmental lead exposure induces depressive-like behavior in female rats. Drug Chem. Toxicol. 28, 67-77. doi: 10.1081/dct-200039696

Diaz-Ruiz, A., Tristán-López, L. A., Medrano-Gómez, K. I., TorresDomínguez, J. A., Ríos, C., and Montes, S. (2017). Glazed clay pottery and lead exposure in Mexico: current experimental evidence. Nutr. Neurosci. 20, 513-518. doi: 10.1080/1028415x.2016.1193967

Elliott, D. S., Huizinga, D., and Menard, S. (1989). Multiple Problem Youth: Delinquency, Substance Use, and Mental Health Problems. New York, NY: Springer-Verlag.

Farrington, D. P. (1998). "Individual differences in offending," in The Handbook of Crime and Punishment, ed. M. Tonry (New York, NY: Oxford University Press), 241-268.

Ferrari, P. F., Palanza, P., Parmigiani, S., de Almeida, R. M. M., and Miczek, K. A. (2006). Serotonin and aggressive behavior in rodents and nonhuman primates: predispositions and plasticity. Eur. J. Pharmacol. 526, 259-273. doi: 10.1016/j. ejphar.2005.10.002

Fleshner, M., Laudenslager, M. L., Simons, L., and Maier, S. F. (1989). Reduced serum antibodies associated with social defeat in rats. Physiol. Behav. 45, 1183-1187. doi: 10.1016/0031-9384(89)90107-8

Fontana, D., Lascano, V. M., Solá, N., Martinez, S., Virgolini, M., and Mazzieri, M. R. (2013). Intoxicación Por plomo Y Su tratamiento. Rev. Salud Pública 1, 49-59.

García, A. G., Claudio, L., Pérez, S. F., and Ríos, C. (1999). Lead acetate exposure inhibits nitric synthase activity in capillary and synaptosomal fractions of mouse brain. Toxicol. Sci. 50, 244-248. doi: 10.1093/toxsci/ 50.2 .244

García, A. G., Ramírez, A. V., Balderas, I., Sandoval, J., Escobar, M. L., Ríos, C., et al. (2004). Cognitive deficits in adult rats by lead intoxication are related with regional specific inhibition of cNOS. Behav. Brain Res. 149, 49-59. doi: 10.1016/s0166-4328(03)00195-5

Goodnough, A. (2016a). Flint Weighs Scope of Harm to Children Caused by Lead in Water. New York Times. Available online at: https://www.nytimes.com/20 16/01/30/us/flint-weighs-scope-of-harm-to-children-caused-by-lead-in-water .html?_r $=0$

Goodnough, A. (2016b). Their Soil Toxic, 1,100 Indiana Residents Scramble to Find New Homes. New York Times, (news story). U.S. section, online edition. Available online at: https://www.nytimes.com/2016/08/31/us/lead -contamination-public-housing-east-chicago-indiana.html [accessed 6 July 2017].

Hawkins, R. D., Son, H., and Arancio, O. (1998). Nitric oxide as a retrograde messenger during long-term potentiation in hippocampus. Prog. Brain Res. 118, 155-172. doi: 10.1016/s0079-6123(08)63206-9

Hirsch, D. B., Steiner, J. P., Dawson, T. M., Mammen, A., Hayek, E., and Snyder, S. H. (1993). Neurotransmitter release regulated by nitric oxide in PC-12 cells and brain synaptosomes. Curr. Biol. 3, 749-754. doi: 10.1016/09609822(93)90022-g 
Hopper, R. A., and Garthwaite, J. (2006). Tonic and phasic nitric oxide signals in hippocampal long-term potentiation. J. Neurosci. 26, 11513-11521. doi: 10.1523/JNEUROSCI.2259-06.2006

Hou, L., Zhang, X., Wang, D., and Baccarelli, A. (2012). Environmental chemical exposures and human epigenetics. Int. J. Epidemiol. 41, 79-105. doi: 10.1093/ije/dyr154

Huang, P. L., Dawson, T. M., Bredt, D. S., Snyder, S. H., and Fishman, M. C. (1993). Targeted disruption of the neuronal nitric oxide synthase gene. Cell 75, 1273-1286. doi: 10.1016/0092-8674(93)90615-w

Huang, P. L., Huang, Z., Mashimo, H., Bloch, K. D., Moskowitz, M. A., Bevan, J. A., et al. (1995). Hypertension in mice lacking the gene for endothelial nitric oxide synthase. Nature 377, 239-242. doi: 10.1038/377239a0

Hwang, L. (2007). Environmental stressors and violence: lead and polychlorinated biphenyls. Rev. Environ. Health 22, 313-328. doi: 10.1515/reveh.2007. 22.4 .313

Karolewicz, B., Paul, I. A., and Antkiewicz-Michaluk, L. (2001). Effect of NOS inhibitor on forced swim test and neurotransmitters turnover in the mouse brain. Pol. J. Pharmacol. 53, 587-596.

Ko, G. Y., and Kelly, P. T. (1999). Nitric oxide acts as a postsynaptic signaling molecule in calcium/calmodulin-induced synaptic potentiation in hippocampal CA1 pyramidal neurons. J. Neurosci. 19, 6784-6794. doi: 10.1523/JNEUROSCI.19-16-06784.1999

Kumar, N., Krishnani, K. K., Kumar, P., Jha, A. K., Gupta, S. K., and Singh, N. P. (2017). Dietary zinc promotes immuno-biochemical plasticity and protects fish against multiple stresses. Fish Shellfish Immunol. 62, 184-194. doi: 10.1016/j.fsi. 2017.01.017

Lanphear, B. P., Dietrich, K., Auinger, P., and Cox, C. (2000). Cognitive deficits associated with blood lead concentrations $<10$ microg/dl in U.S. Public Health Rep. 115, 521-529. doi: 10.1093/phr/115.6.521

Lasley, S. M., Greenland, R. D., Minnema, D. J., and Michaelson, I. A. (1984). Influence of chronic inorganic lead exposure on regional dopamine and 5-hydroxytryptamine turnover in rat brain. Neurochem. Res. 9, 1675-1688. doi: $10.1007 /$ bf00968078

Leret, M. L., Garcia, U. F., and Antonio, M. T. (2002). Effects of maternal lead administration on monoaminergic, GABAergic and glutamatergic systems. Brain Res. Bull. 58, 469-473. doi: 10.1016/s0361-9230(02)00819-5

Lorenc-Koci, E., Czarnecka, A., Lenda, T., Kamińska, K., and Konieczny, J. (2013). Molsidomine, a nitric oxide donor, modulates rotational behavior and monoamine metabolism in 6-OHDA lesioned rats treated chronically with LDOPA. Neurochem. Int. 63, 790-804. doi: 10.1016/j.neuint.2013.09.021

Maiti, A. K., Saha, N. C., More, S. S., Panigrahi, A. K., and Paul, G. (2017). Neuroprotective efficacy of mitochondrial antioxidant MitoQ in suppressing peroxynitrite-mediated mitochondrial dysfunction inflicted by lead toxicity in the rat brain. Neurotox. Res. 31, 358-372. doi: 10.1007/s12640-0169692-7

Markowitz, G., and Rosner, R. (2013). Lead Wars: The Politics of Science and the Fate of America's Children. Berkeley, CA: University of California Press.

Martínez-Lazcano, J. C., Pérez-Severiano, F., Escalante, B., Ramírez-Emiliano, J., Vergara, P., González, R. O., et al. (2007). Selective protection against oxidative damage in brain of mice with a targeted disruption of the neuronal nitric oxide synthase gene. J. Neurosci. Res. 85, 1391-1402. doi: 10.1002/jnr. 21261

Massó-González, E. L., and Antonio-García, M. T. (2009). Natural antioxidants protect against lead-induced damage during pregnancy and lactation in rat's pups. Ecotoxicol. Environ. Saf. 72, 2137-2142. doi: 10.1016/j.ecoenv.2009. 03.013

Miller, K. J., and Hoffman, B. J. (1994). Adenosine A3 receptors regulate serotonin transport via nitric oxide and cGMP. J. Biol. Chem. 269, 27351-27356.

Moffitt, T. E. (1990). "Neuropsychology of juvenile delinquency: a critical review," in Crime and Justice: A Review of Research (Vol. 12) eds N. Morris and M. Tonry (Chicago, IL: University of Chicago Press), 99-169.

Monnet-Tschudi, F., Zurich, M. G., Boschat, C., Corbaz, A., and Honegger, P. (2006). Involvement of environmental mercury and lead in the etiology of neurodegenerative diseases. Rev. Environ. Health 21, 105-117. doi: 10.1515/reveh.2006.21.2.105

National Toxicology Program. (2012). NTP Monograph Health Effects of Low-Level Lead. Research Triangle Park, NC: National Institute of Environmental Health
Science, National Toxicology Program. Available online at: https://ntp.niehs. nih.gov/go/36443

Needleman, H. (2004). Lead poisoning. Annu. Rev. Med. 55, 209-222. doi: 10.1146/annurev.med.55.091902.103653

Norma Oficial Mexicana. (2007). "NOM-231-SSA1-2002, alfarería vidriada, cerámica vidriada y porcelana. Límites de plomo y cadmio solubles," in Método de Ensayo. Diario Oficial de La Federación (SEGOB), 31-40.

Opler, M. G. A., Buka, S. L., Groeger, J., McKeague, I., Wei, C., FactorLitvak, P., et al. (2008). Prenatal exposure to lead, delta-aminolevulinic acid and schizophrenia: further evidence. Environ. Health Perspect. 116, 1586-1590. doi: 10.1289/ehp.10464

Pell, M. B., and Schneyer, J. (2016). Off the Charts: The Thousands of U.S. lOcales Where Lead Poisoning is Worse than in Flint. Available online at: http://www.reuters.com/investigates/special-report/usa-leadtesting/

Pihl, R. O., and Ervin, F. (1990). Lead and cadmium levels in violent criminals. Psychol. Rep. 66, 839-844. doi: 10.2466/pr0.66.3.839-844

Reuben, A., Caspi, A., Belsky, D. W., Broadbent, J., Harrington, H., Sugden, K., et al. (2017). Association of childhood blood lead levels with cognitive function and socioeconomic status at age 38 years and with IQ change and socioeconomic mobility between childhood and adulthood. JAMA 317, 1244-1251. doi: 10.1001/jama.2017.1712

Reyes, J. W. (2015). Lead exposure and behavior: effects on antisocial and risky behavior among children and adolescents. Econ. Inq. 53, 1580-1605. doi: 10.1111 /ecin. 12202

Sampson, R. J., and Winter, A. S. (2018). Poisoned development assessing childhood lead exposure as a cause of crime in a birth cohort followed through adolescence. Criminology 56, 269-301. doi: 10.1111/1745-9125. 12171

Sanders, T., Liu, Y., Buchner, V., and Tchounwou, P. B. (2009). Neurotoxic effects and biomarkers of lead exposure: a review. Rev. Environ. Health 24, 15-45. doi: 10.1515/reveh.2009.24.1.15

Sansar, W., Bouyatas, M., Ahboucha, S., and Gamrani, H. (2012). Effects of chronic lead intoxication on rat serotoninergic system and anxiety behavior. Acta Histochem. 114, 41-45. doi: 10.1016/j.acthis.2011.02.003

Schuman, E. M., and Madison, D. V. (1991). A requirement for the intercellular messenger nitric oxide in long-term potentiation. Science 254, 1503-1506. doi: 10.1126/science.1720572

Soria, F. C., Pérez, V. M., Flores, S. M., and Feria, V. A. (2008). Papel de la serotonina en la conducta agresiva. Rev. Mex. Neurocienc. 9, 480-489.

Stefanski, V. (2001). Social stress in laboratory rats: behavior, immune function, and tumor metastasis. Physiol. Behav. 73, 385-391. doi: 10.1016/s00319384(01)00495-4

Tong, S., von Schirnding, Y. E., and Prapamontol, T. (2000). Environmental lead exposure: a public health problem of global dimensions. Bull. World Health Organ. 78, 1068-1077.

Trope, I., Lopez-Villegas, D., Cecil, K. M., and Lenkinski, R. E. (2001). Exposure to lead appears to selectively alter metabolism of cortical gray matter. Pediatrics 107, 1437-1442. doi: 10.1542/peds.107.6.1437

Virgolini, M. B., and Cancela, L. M. (2014). Exposición a plomo y adicción a drogas (Lead exposure and drug addiction). Rev. Farm. Chile 7, 26-38.

Wang, D., Szyf, M., Benkelfat, C., Provençal, N., Turecki, G., Caramaschi, D. et al. (2012). Peripheral SLC6A4 DNA methylation is associated with in vivo measures of human brain serotonin synthesis and childhood physical aggression. PLoS One 7:e39501. doi: 10.1371/journal.pone.0039501

Weisskopf, M. G., Proctor, S. P., Wright, R. O., Schwartz, J., Spiro, A., Sparrow, D., et al. (2007). Cumulative lead exposure and cognitive performance among elderly men. Epidemiology 18, 59-66. doi: 10.1097/01.ede.0000248237.35 363.29

Weston, H. I., Weston, D. D., Allen, J. L., and Cory-Slechta, D. A. (2014). Sexdependent impacts of low-level lead exposure and prenatal stress on impulsive choice behavior and associated biochemical and neurochemical manifestations. Neurotoxicology 44, 169-183. doi: 10.1016/j.neuro.2014.06.013

Winter, A. S., and Sampson, R. J. (2017). From lead exposure in early childhood to adolescent health: a Chicago birth cohort. Am. J. Public Health 107, 1496-1501. doi: 10.2105/ajph.2017.303903

Wright, J. P., Dietrich, K. N., Ris, M. D., Hornung, R. W., Wessel, S. D., Lanphear, B. P., et al. (2008). Association of prenatal and childhood blood 
lead concentrations with criminal arrests in early adulthood. PLoS Med. 5:e101. doi: 10.1371/journal.pmed.0050101

Yang, Q. Q., Xue, W. Z., Zou, R. X., Xu, Y., Du, Y., Wang, S., et al. (2016). $\beta$-asarone rescues pb-induced impairments of spatial memory and synaptogenesis in rats. PLoS One 11:e0167401. doi: 10.1371/journal.pone.0167401

Zhang, S., Chen, J., and Wang, S. (1998). Spatial learning and memory induce up-regulation of nitric oxide-producing neurons in rat brain. Brain Res. 801, 101-106. doi: 10.1016/s0006-8993(98)00564-2

Zou, L. B., Yamada, K., Tanaka, T., Kameyama, T., and Nabeshima, T. (1998). Nitric oxide synthase inhibitors impair reference memory formation in a arm maze task in rats. Neuropharmacology 37, 323-330. doi: 10.1016/s00283908(98)00042-2
Conflict of Interest Statement: The authors declare that the research was conducted in the absence of any commercial or financial relationships that could be construed as a potential conflict of interest.

Copyright (๑) 2018 Martínez-Lazcano, López-Quiroz, Alcantar-Almaraz, Montes, Sánchez-Mendoza, Alcaraz-Zubeldia, Tristán-López, Sánchez-Hernández, MoralesMartínez, Ríos and Pérez-Severiano. This is an open-access article distributed under the terms of the Creative Commons Attribution License (CC BY). The use, distribution or reproduction in other forums is permitted, provided the original author(s) and the copyright owner(s) are credited and that the original publication in this journal is cited, in accordance with accepted academic practice. No use, distribution or reproduction is permitted which does not comply with these terms. 